\title{
Visually low-impacting methods for the measurement of parameters related to IAQ risk indicators in exhibition halls
}

\author{
Laura Cirrincione ${ }^{1, *}$, Patrizia Ferrante ${ }^{1}$, Maria La Gennusa $^{1}$, Giorgia Peri $^{1}$, Gianfranco \\ Rizzo $^{1}$, and Gianluca Scaccianoce ${ }^{1}$ \\ ${ }^{1}$ Department of Engineering, University of Palermo, Viale delle Scienze Bld. 9 Palermo, Italy
}

\begin{abstract}
Microclimate for cultural heritage plays a fundamental role in the degradation process of artefacts exhibited in museums. Generally, the Indoor Air Quality (IAQ) monitoring inside museums is based on conventional measurements of thermo-hygrometry parameters and longtime averaged measurements of atmospheric pollutants' concentration. Unfortunately, all these approaches require electric supply and are usually characterized by a noticeable visual impact on the exhibition space, which clearly negatively affects the visitors' experience. This paper intends to revisit and discuss a methodology (and its test application on field, to estimate the risk of damage of three artefacts displayed in an old museum of Palermo - Italy) perhaps prematurely underestimated that could usefully be re-proposed in particular contexts in which it is necessary to be careful to be as less invasive as possible, as in the case of museums housed in buildings of particular historical-cultural prestige. The discussed approach uses a non-destructive (or minimally invasive, at least) technique consisting in using two types of coupons, bi-metallic and marble ones, that allows an off-line monitoring of the indoor air aggressiveness inside museums, while avoiding consuming electricity and undesirable visual impacts on the site. Specifically, the estimated coupon damage is regarded as gauge to air aggressiveness, in order to provide an early warning of the risk of damage for the artefacts made of materials similar to those which the coupons are made of. Based on the considerations reported in the paper, the indirect evaluation of the air chemical aggressiveness through the assessment of the bi-metallic and marble coupons' erosion seems to still candidates itself as a feasible method to be applied in complex exhibition scenes.
\end{abstract}

Keywords: museums, indoor air quality, off-line sensors, low visual impact, corrosion risk, artefact preservation, visitors 'comfort.

\footnotetext{
* Corresponding author: laura.cirrincione@unipa.it
} 


\section{Introduction}

Microclimate for cultural heritage plays a fundamental role in the degradation process of artefacts exhibited in museums. In fact, every artefact undergoes a certain biological, chemical and mechanical deterioration over time, likely caused by environmental factors such as air temperature $(\mathrm{T})$, relative humidity $(\mathrm{RH})$, light, gaseous pollutants, and dust. Sudden variations in $\mathrm{T}$ and $\mathrm{RH}$ can, for instance, induce internal stresses, which could in turn generate cumulative and irreversible alterations of the chemical and physical properties of the artefacts, so as to accelerate their degradation [1].

To avoid such circumstances, and thus preserving the important cultural heritage items stored within museums, indoor environmental conditions inside the exhibition halls should be properly monitored and controlled [2,3]. The monitoring task is made even more complex when displayed pieces are made of different materials, in such a case same environmental microclimatic conditions may indeed lead to very different types of decay.

With this aim, several regulations and technical standards at international, European, and national level have been released. At international level, for instance, the ISO 11799 [4] can be cited, which specifies the requirements for the long-term storage of archive and library materials. In addition, in the ASHRAE handbook - HVAC Application [5], a specific chapter is dedicated to museums, galleries, archives, and libraries. While at European level, the EN 15757 [6] need to mentioned, representing one of the most important standards aimed at museums, galleries, storage areas, archives, libraries, churches and modern or historical buildings. This standard, in order to limit climate-induced physical damage on long-term stored/exhibited hygroscopic organic materials, specifies $\mathrm{T}$ and $\mathrm{RH}$ levels to maintain in the indoor environments. At national level, the UNI 10829 [7] can be mentioned. Such regulation prescribes a methodology for the on-field measurement of environmental thermo-hygrometric and lighting quantities for the purposes of proper conservation of historical and artistic goods and provides information on the methods to adopt for processing and synthesize the data collected for their evaluation aimed at containing decay processes.

On the other hand, museums have increasingly become attractive to people that, other than visiting the exhibitions, tend to spend more time inside their premises as other cultural and leisure activities (that, on the other side, are, e.g., responsible of VOCs emissions) are provided [8].

This, in turn, calls for a better assessment of the indoor microclimate parameters inside museums, with the aim of maintaining them at comfort conditions for visiting people and, at the same time, ensuring safety conditions for the works of art [9]. This is particularly important in the case of museums located inside historical buildings $[10,11]$ because this category of buildings is often not equipped with Heating, Ventilating and Air-Conditioning (HVAC) systems.

According to the above-cited standards, a suitable indoor air quality (IAQ) in museums should be indeed characterized by microclimate parameters and pollutants' concentrations, which provide an acceptable compromise between visitors' comfort and appropriate preservation conditions of the artefacts. In this regard, some efforts have been made in order to identify a possible common area of application between indoor requisites for the artefacts' preservation and the people's comfort in museums [12,13].

Generally, the IAQ monitoring inside museums is based on conventional measurements of thermo-hygrometric parameters and on long-time averaged measurements of atmospheric pollutants' concentration. These measurements can be made using both on-line and off-line methods [14] and are typically taken by means of fixed equipment such as dosimeters [15, 16] and sensors whose operating principles are based on electrical resistivity measurements $[17,18]$. The use of colorimetric sensor arrays has also been 
proposed to identify air pollutants commonly present in museums [19]. Additionally, methods that can work remotely using wireless technology and Internet connection [20, 21, 22], smart technological approaches [23] and numerical modelling [24] have also been proposed for monitoring purposes.

Unfortunately, almost all these approaches require a power supply and are generally characterized by a noticeable visual impact on the exhibition space, which clearly negatively affects the visitors' experience, as well as making them unreliable in the event that disservices in the supply of electricity occur.

This paper intends to revisit and discuss a methodology (and its test application on field, to estimate the risk of damage of three artefacts displayed in an old museum of Palermo Italy) perhaps prematurely underestimated that could usefully be re-proposed in particular contexts in which it is necessary to be careful to be as less invasive as possible, as in the case of museums housed in buildings of particular historical-cultural prestige. Such methodology allows an off-line monitoring of IAQ-related indoor parameters inside museums, so as to verify their accordance with those suggested by the pertinent standards, while avoiding the use of electricity and undesirable visual impacts on the exhibition scene. Specifically, this approach uses a non-destructive (or minimally invasive, at least) technique consisting in using two types of coupons: bi-metallic and marble ones.

\section{Materials and Methods}

The basic idea of the methodology is to use specific materials, such as metallic and marble, to measure the actual physical and/or chemical stress inflicted on the artefact by the air present in the exhibition halls where they are displayed. Data obtained from coupons' analysis allow to evaluate the given environment in terms of risk of damage for the artefacts. In other words, the estimated coupon damage, in terms of corrosion/alteration of the sensor properties, is regarded as a gauge of air aggressiveness, in order to provide an early warning of the risk of damage for the artefacts made of materials similar to those of which the coupons are made.

Corrosion/alteration phenomena are indeed linked both to the presence of aggressive/acid pollutants in the air and to indoor environmental characteristics, especially relative humidity values. In particular, concerning the marble coupons, these conditions lead to an alteration of the mechanical properties of the material. Specifically, a modification of the hardness characteristics due to the fact that the aggressive film alters the chemical structure of the surface layer of marble [25]. As regards the metal coupons, corrosion is linked to the formation of a thin film on the layer of the metal foil due to an electrolysis phenomenon, which is however hindered if the layer of the film becomes too thick, i.e. if there is a high value of relative humidity, i.e. generally for values higher than $70 \%[26]$.

The first of the two IAQ off-line measurement methods consists in the use of bi-metallic coupons. It is a reactive-corrosive method, originally used in the industrial sector, which has been proposed for the application in museums by the "Comitato Termotecnico Italiano" (Italian Thermo-technical Committee). This approach consists in the use of a coupon containing two metallic samples, i.e. copper and silver, which is placed together with the considered work of art over an extended period of time; once the established time is passed, the reactivity of the two metals is measured and the thickness of the layer of corrosive product - used as gauge of the reactivity of the polluted air - is calculated using Equation (1) $[26,27,28,29]$.

$$
x=k \cdot t^{n}
$$


where:

- $x$ represents the thickness of the layer of corrosive product, measured in $\AA$;

$-k$ is a constant related to the cause or causes of corrosion;

$-t$ represents the exposure time, measured in days;

$-n$ is a constant that expresses the relationship between $x$ and $k$.

For comparative analysis, and under the same conditions of exposure, the proportionality constant, $k$, has no longer any influence and; therefore, the function $n$ can be given by $n=0.504 \cdot(x / 2000)^{2}+0.244 \cdot(x / 2000)+0.252$, or be assumed equal to 0.3 (light effect), 0.5 (moderate effect) or 1 (severe effect) on the basis of the reactivity level of the air under investigation, as suggested by the ISA Regulation [28] for industrial environments.

The bi-metallic coupons used in the test application were the Purafil ${ }^{T M}$ (Figure 1); it was therefore chosen to use the environmental classification proposed by Purafil ${ }^{T M}$ company to correlate the obtained results with the levels of danger for the artefacts; in particular, the warning limits are 250-350 $\AA / 30$ days for copper corrosion and 200-300 $\AA / 30$ days for silver corrosion $[28,29]$. As a precaution, the overall threshold for which attention is required was set at $200 \AA / 30$ days.
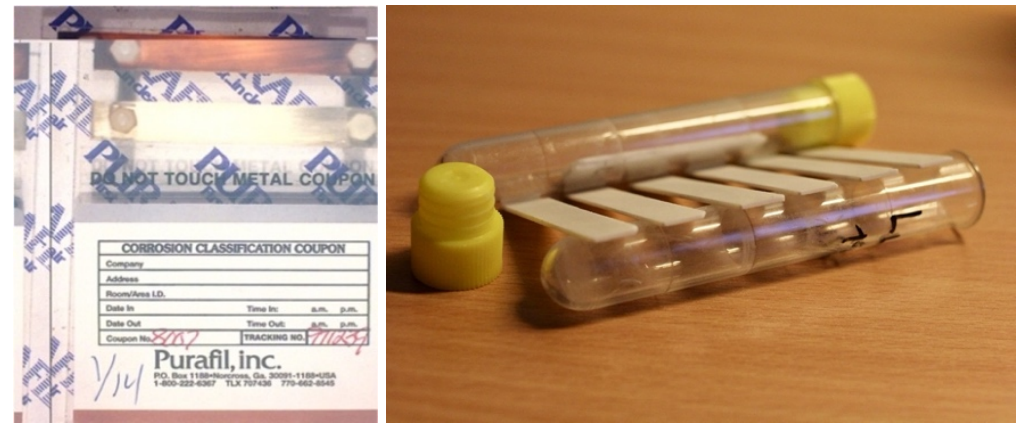

Fig. 1. Purafil ${ }^{T M}$ bi-metallic reactive coupon (on the left) and marble coupons (on the right; courtesy of prof. Livio De Santoli, Università di Roma Sapienza), used for the IAQ monitoring.

The second IAQ off-line measurement method consists in the use of marble coupons in the form of small marble strips (Figure 1), also in this case the air pollution is evaluated on the basis of marble reactivity to the considered environment; in particular the pollution levels are related to the mechanical degradation of the marble on display (together with the artefact) after a certain period of time.

Hardness, $H V_{0,2}\left(\mathrm{~N} / \mathrm{mm}^{2}\right)$, is the mechanical property indicating the resistance of a material; in this case, the marble resistance was obtained via the Vickers' method (Equation 2 ). That is, cutting the surface of the coupon with a square-based pyramidal indenter at an

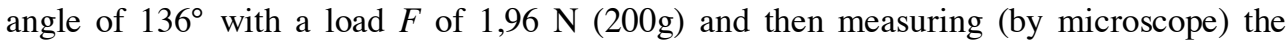
diagonal $d(\mathrm{~mm})$ of the mark left by the indenter. A number of tests were performed for each coupon, in order to assess their average hardness value $[26,30]$.

$$
H V_{0.2}=1854 \cdot F / d^{2}
$$

As earlier stated, this approach was tested by means of an application aimed at estimating the risk of damage of three artefacts displayed in an old museum of Palermo (Italy). Specifically, a monitoring campaign was conducted in the "Museo Regionale" of 
Palermo housed in the heritage building Palazzo Abatellis, campaign finalized at detecting the indoor air aggressiveness. The considered artefacts (Figure 2), were the following:

- the Triumph of Death, a fresco considered one of the most representative works of the late Gothic painting in Italy. The author of the work, which dates back to the year 1446, is unknown;

- the Virgin Annunciate, a painting by the Italian Renaissance artist Antonello da Messina; probably painted in Sicily in the year 1476, it shows Mary interrupted at her reading by the Angel of the Annunciation;

- the "Alhambra" Malaga Amphora, valuable example of a metallic luster painted pottery (loza dorada) with an inscription in Cufic characters, Officine di Malaga, 14th century.
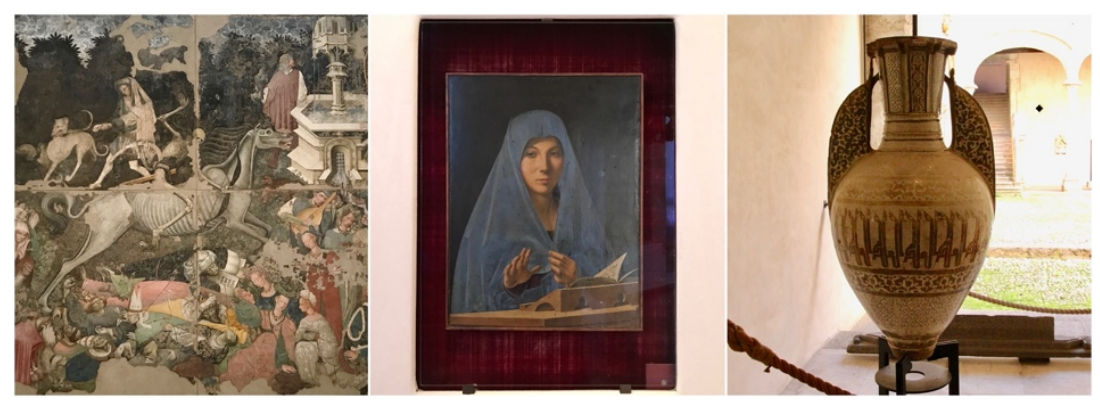

Fig. 2. From left to right Triumph of Death, Virgin Annunciate, "Alhambra" Malaga Amphora.

The bi-metallic reactive coupons were placed in the exhibition halls hosting the three considered artefacts using small wooden frames; moreover, another coupon was installed inside the Virgin Annunciate case, in order to detect possible micro-climatic variations between the room environment and the atmosphere surrounding the painting.

Regarding the monitoring period, the coupons relative to the Virgin Annunciate, its case and the Triumph of Death remained in place for three months; while for the "Alhambra" Malaga Amphora it was chosen to use three different coupons, which stayed in place for a period of one month each (investigated period: from October to December).

The marble coupons were positioned in the same places as the bi-metallic ones and each of them remained in place for approximately six months (investigated period: from August to January) before being tested.

\section{Results}

This section summarizes the outcomes of the methodology test application on field for the two types of coupons.

The results related to the bi-metallic coupons (chemical degradation) are reported in short in Figure 3. 


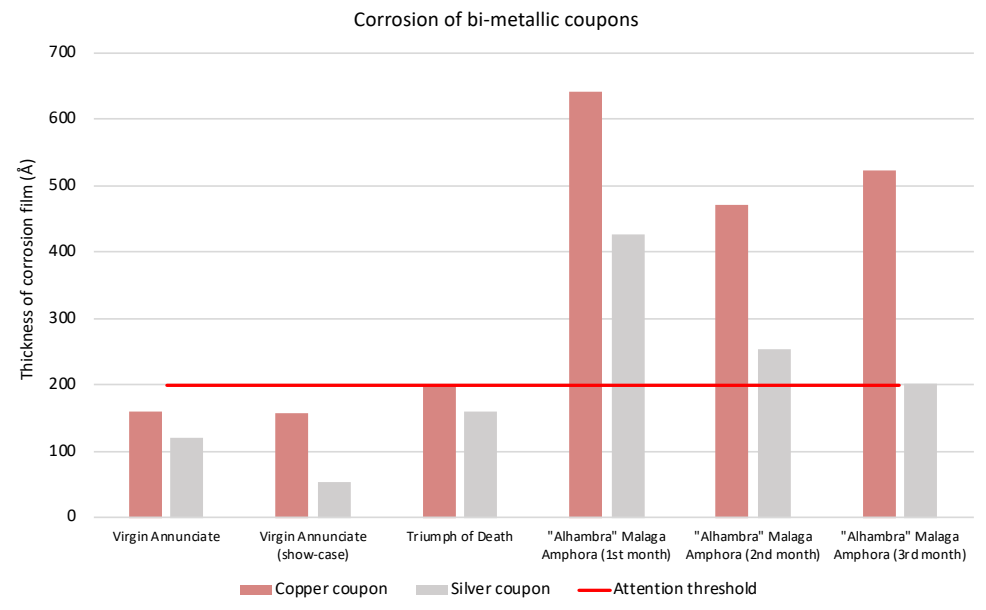

Fig. 3. Results of the Purafil ${ }^{T M}$ bi-metallic reactive coupon application. The continuous horizontal line indicates the overall threshold for which attention is required.

As it can be noted from Figure 3, the air quality can be considered acceptable, though not totally satisfactory for the Virgin Annunciate and the Triumph of Death; it is also evident the effect of the Virgin Annunciate protective case, particularly on the silver coupon as showed by the lower obtained values compared to those of the coupons placed outside the protective case. The microclimate surrounding the "Alhambra" Malaga Amphora is, instead, such that the thickness of corrosion is constantly over the danger threshold. This result may be justified by the fact that it is positioned in a room of the building that is significantly exposed to external environmental conditions.

Regarding the use of the marble coupons (physical degradation), the application results shown values consistent with those of the bimetallic coupons. In fact, the marble coupons positioned in the hall hosting the Virgin Annunciate had an average hardness (123.3 \pm 6.6 $\left.\mathrm{N} / \mathrm{mm}^{2}\right)$ higher than that of the coupons placed in the Triumph of Death hall $(122.3 \pm 7.6$ $\mathrm{N} / \mathrm{mm}^{2}$ ), and lower than the one of the coupons placed near the "Alhambra" Malaga Amphora $\left(120.5 \pm 9.4 \mathrm{~N} / \mathrm{mm}^{2}\right)$.

It must be noted that unfortunately for this methodology, unlike bi-metallic coupons, there is no reference scale that allows an environmental classification. Nonetheless, based on the values of the third column it can be inferred that the "Alhambra" Malaga Amphora appears to have been exposed to a more aggressive air than that to which the other two works of art were subjected. This result, as already mentioned, is perfectly in line with the results obtained from the bi-metallic coupons.

\section{Discussion}

The choice to resume the thematic related to the use of passive sensors for assessing the indoor air aggressiveness in museums arises from considerations concerning to the possibility of going opposite the current trend aimed at the increasingly pushed use of electronic sensors which, although now very small in size, generally need a continuous power supply and, most importantly, are more expensive and therefore, since they are left in places open to the public, could turn into economic concerns following possible damage. 
In addition, it should also be considered that off-line sensors often interfere less with the exhibition scene chosen by the curators, as can be seen in Figure 4 which shows a comparative assessment of the visual impact of off-line and on-line sensors.

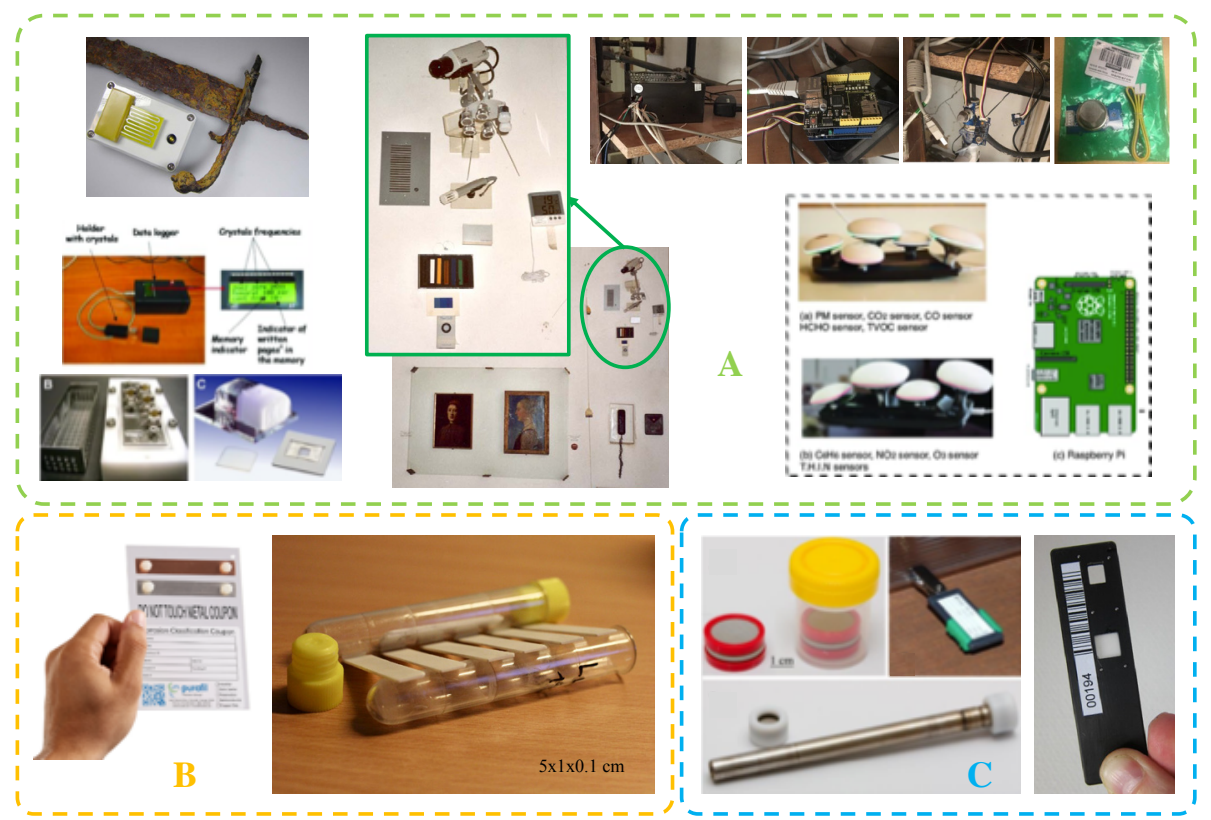

Fig. 4. Visual impact comparison between on-line (A - most utilized methods that rely on electricity) and off-line (B - here discussed bi-metallic Purafil ${ }^{T M}$ and marble coupons - and C - other available types of comparable off-line methods) sensors.

Generally, standards and regulations provide permitted maximum concentration levels only for a limited set of substances (i.e. $\mathrm{SO}_{2}, \mathrm{O}_{3}, \mathrm{NO}_{x}, \mathrm{PM}$ ) and suggested monitoring methods frequently involve the use of equipment capable of monitoring such substances separately and, other than being expensive and requiring constant energy supply, often also produce a noticeable visual impact that conflicts with the requisites of artefacts' exhibition [13]. Furthermore, it must be said that it is still difficult to associate the concentration of one or more pollutants with the overall aggressiveness of the air inside an environment, and therefore with the possible damage caused to a work of art.

In light of this, efforts have been made over the years to find IAQ measurement methods that pay particular attention to material risks of deterioration, minimum demand of electricity and low impact on the visual scene, and which can also be easily implemented and managed at a low cost.

Regarding IAQ monitoring in museums, generally speaking it can be realized by directly measuring the pollutants concentrations continuously, on-line, or via the use of sensors which usually works off-line. The variation in physical and/or chemical characteristics of specific coupons to be placed in the proximity of the considered work of art for a certain period of time represent an interesting option, since it is based on the evaluation of the comprehensive deterioration effects that air pollutant substances, combined between them, have on the artefacts.

In consideration of this, the here discussed off-line indirect methods thus address the IAQ monitoring in museums according to a point of view reverse to the traditional one. Specifically: rather than measuring the pollutants concentrations, the IAQ is assessed on the 
basis of physical and chemical deterioration measures of coupons made of specific materials (copper, silver and marble) which have deterioration's characteristics similar to those of some types of artefacts.

Also, this approach is a good compromise between the need of an accurate detection of the IAQ of the room and (the need) of avoiding the modification of the visual rendering of the site, which is an important aspect in the context of exhibition halls.

Although this indirect evaluation of the chemical aggressiveness of the air, by means of the assessment of the erosion of bi-metallic and marble coupons, candidates itself as a feasible method to be applied even in complex exhibition scenes, the proposed approach also has some limitations, the main of which is in that the information obtained by analysing the coupons is valid only for materials that have a similar reactivity to that of the sample material. In addition to this, another limit is represented by the fact that it is not possible to conduct continuous and/or real-time monitoring [26].

In order to draw some additional considerations, it was here decided to estimate the risk of damage for the considered artefacts on the basis of an internationally known method, namely the Equilibrium Moisture Content $(E M C)$, i.e. the moisture content reached at the equilibrium state with the indoor environmental $\mathrm{T}$ and $\mathrm{RH}$ values [25], to compare the results with those related to the coupons technique. This further investigation was particularly aimed at assessing whether the influence of the presence of pollutants in the environment was predominant over the characteristics of $\mathrm{T}$ and $\mathrm{RH}$.

For the $E M C$ calculation the approach proposed by the Image Permanence Institute (IPI) was considered. IPI has indeed developed some Preservation Metrics [31, 32] in order to transform $T$ and $R H$ data into quantitative numerical measures for collections' decay risk. Specifically, metrics for chemical damage, dimensional change or mechanical damage, potential for biological decay or mould risk growth and moisture-induced corrosion were developed. Each metric evaluates the quality of the considered environments over a period of time, using a single value that represents the degree of risk for a particular form of damage, taking into account the fluctuations of $\mathrm{T}$ and $\mathrm{RH}$ during the monitoring period. According to these metrics environments are rated as "Good" or "Risk" based on the EMC values obtained from the monitored data of $\mathrm{T}$ and $\mathrm{RH}$.

In this case, only the evaluation rates relative to corrosion were considered. That is: if the maximum \% EMC is lower than 12.5 then the environment is classified as "Good", otherwise it is classified as "Risk".

The calculation of EMC values for the selected environments was carried out on the basis of environmental data of T and RH that were monitored in the examined museum halls for a whole year [33]. The formula used for the EMC calculation is that proposed by IPI and reported in [32]. The parameters involved in the formula are $\mathrm{T}\left({ }^{\circ} \mathrm{C}\right), \mathrm{RH}(\%)$, and adsorption coefficients, $W, K, K_{l}, K_{2}$. Each coefficient is, in turn, a function of T.

Table 1 shows the obtained $E M C$ values corresponding to the monitored $\mathrm{T}$ and $\mathrm{RH}$ data in the exhibition halls during the periods of time where both the bi-metallic and marble coupons were positioned.

Table 1. EMC values obtained in the present analysis.

\begin{tabular}{l|cc|cc}
\hline & \multicolumn{2}{|c|}{ Bi-metallic coupons } & \multicolumn{2}{c}{ Marble coupons } \\
\hline & Min \% & Max \% & Min \% & Max \% \\
Virgin Annunciate & 4,53 & 4,68 & 4,36 & 4,70 \\
Triumph of Death & 4,55 & 4,70 & 4,40 & 4,73 \\
"Alhambra" Malaga Amphora & 4,53 & 4,74 & 4,41 & 4,81 \\
\hline
\end{tabular}


Comparing the obtained EMC values (Table 1) with the previously cited evaluation scales proposed by the IPI, it can be noted that for all artefacts the percentages are always lower than 12.5; this result signals that the risk of corrosion damage should not be present. This contrasts the results obtained by using the bi-metallic and marble coupons for the "Alhambra" Malaga Amphora. Therefore, the potential damage risk conditions obtained by analysing the coupons would be mainly attributable to the aggressiveness of the air inside the monitored environments in terms of polluting substances.

To sum up, comparing the data obtained by the coupons' analysis and the calculated $E M C$ values, it is possible to infer that the presented measurement methods result more sensible to the actual pollution levels inside such environments.

Anyhow, as previously mentioned, given the ambiguity of current regulations, concerning the fact that an acceptable compromise between the visitors' comfort and the proper works of art's preserving conditions in museum should be obtained by maintaining intermediate microclimate parameters levels, it is not possible to determine precisely whether the bi-metallic and marble coupons methods comply with such standards or not. To this purpose further research analysis in the field should be carried out in order to implement new standards and regulations which, other than complying to the currently considered general needs (artefacts' preservation and people's comfort), should report precise guidelines and technical rules concerning the use of both low energy-demanding and low visually-impacting measurement equipment tools in exhibition halls (referring to the specific works of art), especially for those hosted in historical buildings.

Following the above-made considerations, the use of passive sensors still seems to constitute a valid alternative to active sensors, for both their simplicity of installation and their low visual impact, as well as for the cost-effectiveness of the material used during the monitoring and for the reliability and safety due to the fact that, not needing to be electrically powered, there would be no loss of data in the event that disservices in the supply of power occur.

In light of this, in the authors opinion, sensors of the type discussed here, which monitor not the value of a single substance, but the aggressiveness of the air on a type of material, still constitute a valid alternative for the overall evaluation of air quality aimed at the works of art conservation.

On the other hand, such off-line sensors cannot be called instantly remotely to read a precise and temporal value of a polluting substance. But this, when works of art are involved, does not represent big problem since for these artifacts any possible damage must be evaluated over a long period of time and as an average of the quality of the environments in which they are exhibited, and not in reference to instant and punctual values of the aggressiveness of the air.

\section{Conclusions}

The present work started from considerations regarding the possibility of give new visibility to electricity-free and visually-low-impacting methods to assess and monitor the overall indoor air aggressiveness inside museums in terms of deterioration of materials.

On purpose, it was decided to discuss the on-field test application, in an old museum sited in Palermo, of a prematurely underestimated methodology based on some peculiar measurement tools, i.e. bi-metallic and marble coupons, whose deepness of erosion over a certain period of time is used as a direct indication of the risk of danger at which works of art present in a given room could be exposed.

The application suggests that the indirect evaluation of the chemical aggressiveness of the air, by means of the assessment of the erosion of bi-metallic coupons, can still represent a feasible method to be applied even in complex exhibition scenes. In fact, such approach 
demonstrates the practicability of performing a measurement of the indoor conditions inside heritage buildings without power supply, avoiding undesired interferences with the displayed works of art and the visual scene and, at the same time, giving useful information regarding the environment aggressiveness in terms of pollution.

In addition, it must be considered that the design of HVAC systems - required to maintain environmental conditions within values suitable for both artefacts' preservation and visitors' comfort - should be pondered with extreme caution, since museum buildings are often cultural heritage themselves; therefore, also the HVAC systems should be characterized by low visual impact, other than by low energy consumption, so as not to conflict with the exhibition scene and the architectural design of the building. Furthermore, these systems should be chosen with proper lighting fixtures capable to guarantee a correct visual perception by people and, at the same time, avoiding damages to the artefacts.

This work was carried out within the research project n. 201594LT3F, "La ricerca per i PAES: una piattaforma per le municipalità partecipanti al Patto dei Sindaci (Research for SEAP: a platform for municipalities taking part in the Covenant of Mayors)", which is funded by the PRIN (Programmi di Ricerca Scientifica di Rilevante Interesse Nazionale) of the Italian Ministry of Education, University and Research.

\section{References}

1. Sharif-Askari, H., Abu-Hijleh, B. Review of museums' indoor environment conditions studies and guidelines and their impact on the museums' artifacts and energy consumption (Article), Building and Environment, Volume 143, 1 October 2018, Pages 186-195

2. Lanteri, L., Pelosi, C., Monaco, A.L., The relevance of monitoring the microclime in museums the case of colle del Duomo in Viterbo, European Journal of Science and Theology, Volume 16, Issue 4, 2020, Pages 181-191

3. M. La Gennusa, F. Nicoletti, G. Rizzo, G. Scaccianoce (2005), "Control of indoor environments in heritage buildings: experimental measurements in an old Italian museum and proposal of a methodology", Journal of Cultural Heritage, 6, 147-155.

4. ISO 11799 (2003), Information and documentation - Document storage requirements for archive and library materials, International Organization for Standardization, Geneva.

5. ASHRAE Handbook-HVAC Applications. Chapter 23: Museums, Galleries, Archives, and Libraries (2011). American Society of Heating, Refrigerating and AirConditioning Engineers Inc.

6. EN 15757:2010 (2010), Conservation of Cultural Property - Specifications for temperature and relative humidity to limit climate-induced mechanical damage in organic hygroscopic materials.

7. UNI 10829:1999 (1999), Artefacts of historical and artistic importance - Conservation environmental conditions - Measurement and analysis (Beni di interesse storico e artistico - Condizioni ambientali di conservazione - Misurazione ed analisi) UNI - Ente Italiano di Unificazione, Milano.

8. Wu, P. Make a loyal visitor: a study of leisure experience at Farglory corporate museum in Taiwan, Asia Pacific Journal of Tourism Research, Volume 22, Issue 5, 4 May 2017, Pages 554-564

9. Schito, E., Conti, P., Testi, D., Multi-objective optimization of microclimate in museums for concurrent reduction of energy needs, visitors' discomfort and artwork preservation risks, Applied Energy, Volume 224, 15 August 2018, Pages 147-159 
10. Martinez-Molina, P. Boarin, I. Tort-Ausina, J. L. Vivancos (2018), “Assessing visitors' thermal comfort in historic museum buildings: Results from a Post-Occupancy Evaluation on a case study", Building and Environment, 132, 291-302

11. Ferdyn-Grygierek, J., Monitoring of indoor air parameters in large museum exhibition halls with and without air-conditioning systems, Building and Environment Volume 107, 1 October 2016, Pages 113-126

12. M. La Gennusa, G. Rizzo, G. Rodonò, G. Scaccianoce (2009), "People comfort and artwork saving in museums: comparing indoor requisites", Int. J. Sustainable Design, 1 (2), 199-222.

13. M. La Gennusa, G. Lascari, G. Rizzo, G. Scaccianoce (2008), "Conflicting needs of the thermal indoor environment of museums: In search of a practical compromise", Journal of Cultural Heritage, 9 (2), 125-134.

14. L. Cartechini, S. Castellini, B. Moroni. Palmieri, F. Scardazza, B. Sebastiani, R. Selvaggi, M. Vagnini, G. L. Delogu, B. G. Brunetti, D. Cappelletti (2015), “Acute episode of black carbon and aerosol contamination in a museum environment: Results of integrated real-time and off-line measurements", Atmospheric Environment, 116, 130-137.

15. T. Grøntoft, D. Thickett, P. Lankester, S. Hackney, J. H. Townsend, K. Ramsholt, M. Garrido (2016), "Assessment of indoor air quality and the risk of damage to cultural heritage objects using MEMORI ${ }^{\circledR}$ dosimetry”, Studies in Conservation, 61:sup1,7082.

16. Cavicchioli, C. A. Neves, R. Inhasz Pavia, D. L. Araùjo de Faria (2014), “An upgraded automatic piezoelectric quartz crystal dosimeter for environmental monitoring in indoor cultural heritage conservation areas", Sensors and Actuators B, 190, 1014-1023.

17. M. Dubus, M. Kouril, T. P. Nguyen, T. Prosek, M. Saheb, J. Tate (2010), "Monitoring Copper and Silver Corrosion in Different Museum Environments by Electrical Resistance Measurement", Studies in Conservation, 55:2, 121-133.

18. T. Prosek, M. Kouril, M. Dubus, M. Taube, V. Hubert, B. Scheffel, Y. Degres, M. Jouannic, D. Thierry (2013), "Real-time monitoring of indoor air corrosivity in cultural heritage institutions with metallic electrical resistance sensors", Studies in Conservation, 58:2, 117-128.

19. Li, Z., Wang, Z., Khan, J., Lagasse, M.K., Suslick, K.S., Ultrasensitive Monitoring of Museum Airborne Pollutants Using a Silver Nanoparticle Sensor Array, ACS Sensors, Volume 5, Issue 9, 25 September 2020, Pages 2783-2791

20. Perles, E. P.rez-Mar.n, R. Mercado, J. Damian Segrelles, I. Blanquer, M. Zarzo, F. J. Garcia-Diego (2018), "An energy-efficient internet of things (IoT) architecture for preventive conservation of cultural heritage", Future Generation Computer Systems, 81, 556-581.

21. D. Ibaseta, J. Molleda, F. Diez, J. C. Granada (2019), “An IOT Platform for Indoor Air Quality Monitoring Using the Web Of Things", Transactions on Ecology and the Environment, 236, WIT Press, www.witpress.com, ISSN 1743-3541.

22. M. Gaudenzi Asinelli, M. S. Serra, J. M. Marimòn, J. S. Espaulella (2018), "The smARTS_Museum_V1: an open hardware device for remote monitoring of Cultural Heritage indoor environments", HardwareX.

23. P. Rea, A. Pelliccio, E. Ottaviano, M. Saccucci (2017), "The Heritage Management and Preservation Using the Mechatronic Survey", International Journal of Architectural Heritage, 11:8, 1121-1132.

24. D. Ladiana, M. Di Sivo (2019), "Programmed Conservation of Historical and Architectural heritage. Tools for Optimising a Process Based on Knowledge and Information", Int. J. of Design \& Nature and Ecodynamics, 14 (3), pp. 229-240.

25. Dario Camuffo, Microclimate for Cultural Heritage (2013), Elsevier. 
26. E. Sacchi (1998), "Il monitoraggio reattivo della qualità dell'aria negli ambienti museali (Parte Prima)", La Termotecnica, Ottobre-Novembre 1998, 89-96.

27. ISA-S71.04 (1985), "Environmental Conditions for Process Measurement and Control Systems: Airborne Contaminants", Instrument Society of America, Research Triangle Park, North Carolina (USA).

28. PURAFIL INC. (1993), "Environmental Control for Museums, Libraries and Archival Storage Areas", Technical Brochure 600 and latest edition 600A, Atlanta, Georgia (USA).

29. PURAFIL INC. (2018), "Product bulletin corrosion classification coupon" www.purafil.com • (C) Purafil 2018 ProdBltn - CCC-4.

30. F. Guidobaldi, E. Petrucci, Romanelli, G. Schirripa Spagnolo, F. De Santis, T. Valente (1995), "Nuovi sensori per la valutazione di indici di rischio per i monumenti in marmo esposti all'aperto", Proceeding of 1st International Congress on Science and Technology for the Safeguard of Cultural Heritage in the Mediterranean Basin, Catania-Siracusa, Italy.

31. D. W. Nishimura, Understanding Preservation Metrics (2011), Image Permanence Institute, Rochester Institute of Technology (https://www.imagepermanenceinstitute.org).

32. W. T. Simpson, Equilibrium Moisture Content of Wood in Outdoor Locations in the United States and Worldwide (1998), Research Note FPL-RN-0268, United States Department of Agriculture.

33. L. Cirrincione, A. Nucara, G. Peri, G. Rizzo, G. Scaccianoce (2020), “Two operative risk indicators as tools for negotiating contracts between curators of Museums and HVAC technical services providers", Journal of Cultural Heritage, 41, 200-210. 